\title{
The Architecture Samplings S_T_A_R_S as the Principle of Sharing Statistically Validated Medical Experiences in Orthopaedics OECD
}

\author{
Antonín Cuc* \\ The international expert in occupational Health and Safety, Czech Technical University, Europe
}

Submission: January 02, 2018; Published: February 05, 2018

*Corresponding author: Antonín Cuc, The international expert in occupational Health and Safety, Czech Technical University, Na Míčánkách 435/1,101 00 Prague 10, Czech Republic, Europe, Email: betruea@gmail.com

\section{Opinion}

In 2010, the World Health Organization WHO organized a global statistical survey of all OECD countries, the error decision of medical procedures in the diagnosis or choosing the right individual therapy and comprehensive forensic medical conclusions are absolutely frightening - that is: irrespective of any medical specialty, regardless Provider health services in outpatient or inpatient care - shows the relative incidence of serious medical errors tragic $10 \%$ of the daily workflow with statistical reliability estimation tolerance of $+/-2 \%$

Medical Assessment Coordination Commission OECD watched only unnecessary medical decision-making serious mistakes - compared to the available medical knowledgebased encyklopedic Sources WHO - was a fatal mistake, which matches the long-term damage to health or lives of patients in the OECD countries. And this fact is yet to be solved by the endless, unreasonable world plague wounded by the Healthcare Providers of the OECD patient community!

This finding has been terribly alarmed in the professional circles of US occupational safety experts at Health Service Providers - and therefore a number of statistical analytical surveys have been conducted in 2012-2016, see Annexes Literature $/ 1 /, / 3 /$ - as it is at all possible informative that in statistics causes of fatalities in the United States, these fatal medical errors are not explicitly recorded anywhere, prevention of repetition is not solved at all, health costs with the insurance company are also paid to the providers of fatal health services even if unnecessary illegal death of the patient. Nowadays, medical errors and medical procedures that have been identified so far have not been used - nor do they help to provide satisfactory social support to survivors, unnecessarily orphaned families.

Unfortunately, what is a much worse feature in a desperate state of mass-error daily medical workflow - which Healthcare Providers and their staff doctors, their fatal error in deciding their own patients deny - they also do not want to know anything about illegality, Physicians do not want to hear explanations from forensic doctors. That's exactly the same in the US as in the Czech Republic - the death of patients due to medical errors, after strokes and carcinomas is the third most frequent common cause of death!. Many apathetic doctors without Ethics enough generally consider their a priori development: for a fair solution, as a well-established, addictive and legally recognizable horrible state - the massive unnecessary and still undeclared mass mortality of their patients - it is covered as Lege artis CZ".

For example - as unnecessary mutilation and dying damage, the patients of the Czech Republic become accustomed - and so consistently still to this day are the Expert Medical Institutes of the Czech Republic, the Judiciary of the Czech Republic, the Criminal Police of the Czech Republic, the Constitutional Court of the Czech Republic! It is a permanent secret civil illegal national internal war, conducted with impunity against its own patients in the Czech Republic, with terrible numbers of about 40,000 annually needless Victims' crippled and prematurely deceased patients of the Czech Republic with the petrification of technically obsolete and illegal medical practices -dehonesting of Mass of finished Medical processing.

Neither I personally, as an experienced state investigator of the causes of the occurrence of fatal occupational accidents at work in the scope of supervision of the Ministry of Labor and Social Affairs of the Czech Republic, I did not succeed with the forensic technical evidences even when I submitted to the Prague Regional Court in writing before the beginning of the Court trials No. 36 C 181/2009 tens of indisputable criminological technical evidence of the crime that I have become too an unnecessary victim of the illicit implantation orthopedic process of the Health Service Provider and his or her poorly orthopaedics, radiologists, Quality managers - when the standard "Classical orthopaedic surgery of the set THA "right hip by usage product B. Braun Germany, implants -set Type“ BICONTACT S.

The Uncemented set" ended with Crash with my deadly unnecessary hall wound "Fausse route of metalic shaft - with 
punctuare moving through right femoral bone by my full Anaesthesia" - when my orthopedist M Dr.. František Vurm - never worked out a mandatory preoperative surgery clinic legal Plan, never he controlled the Punct" Distaly installing Position - Spice of the Component Stem" on reglemented defined coordinates $\mathrm{Xi}, \mathrm{Yi}, \mathrm{Zi}$ - in the functional fixed prescribed coaxial depth of the femoral cavity - according to the rules of the Certified Medical Device Protocol "CE", - when my orthopedist did not respect the hall technologically already preoperatively radiologically diagnosed dysplastic position of the neck of my right femur when my orthopedist performed an inoperative shaft accuracy assembly in the orthopedic hall and did not bring into operation the entire set of hip TEP - with the technical fatal error a metal shaft with an illegal discharge at an false declination angle of 13.68 degrees! - While times the manufacturer explicitly requires certified technical inspection accuracy by radiological company Masks on the orthopedic screen only (not in hands by the intuitive views only) - within tolerance of coaxial angle of the stem with femoral cavity +/- 1 degree!

In such circumstances, the official opinion of the supervised State Institute - SÚKL Prague, the Knowing institute -The Central Military Hospital of Prague, the Criminal Police of Prague 1, the main Prague Public Prosecutor's Office, the Prague Regional Court is an absurd, criminally absurd, fraudulent judgment, 36 C 181 / 2009-221 dated September 24,.2012 - that "everything is evaluated- to be within the normal limits of observing medical work in the usual quality of Orthopedic radiological, organizational conditions of the so-called "LEGE ARTIS CZ" by the virtually Happened as a postoperational Patient Fall?! This Official Court Experts are Idiots and my Murders with permanent placing and in forcing the false Court Medical Hypotheses out of feasible Phenomenons in Physics, Biomechanics, Geometry 3D the blame is on the side of needless dying Patient, The Providers of Health care and Physicians including the Authors of false Medical Court Message No 36 C 181/2009-123 since March 27, 2012 are full scot free and respected by the Judge, including in the false argumented Judgement - while the injured Patient are needless dying "Lege Artis CZ" without all Human Civic Rights $\mathrm{CZ}$ !

That is why I regard this as a proven public criminal organization of a large organized long Being group of several state organizations of the Czech Republic and their dozens of employees: physicians, lawyers, judges of the Czech Republic - by acting with the obvious systematic daily consent of consciously illegal medical processes in the Czech Orthopaedics-contrary legal conditions of safe implantation in the networks of Health Service Providers for safe use according to the "Technical Requirements" of EC Medical Devices under Directive 93/42/ EEC Medical Devices taken in accordance with full Technical requirements in the Czech legislation in force - and therefore a criminal public opinion of the group of my mutually coordinated murderers - against my Constitutional Human Rights to a citizen of the Czech Republic/EU - Patient of the Czech Republic / EU - namely, definitely without respect for my life, without respecting my will be a citizen of the Czech Republic without any rights only usage the legal health care with legal usage Medical Devices "CE" of the Czech Republic and without the right to a fair Court trials only in the sense of preserving the constitutionality processing of the Czech Republic - that is by fair and verifiable criminal forensic evidence, with fair judicial satisfaction for personal rights damage - my causal Shorten life expectancy for many years.

The official conclusion that unnecessary fatal orthopedic mutilation with a frontal femoral breakthrough, with the lifelong complete neurological plegia of my right underknee and forced repeat complete Full Aesthesia, just with an 8x more likely recurrent fatal fall with a recurrent femoral neck fracture consciously caused by ionizing multiple redundant additional RTG over- in The Knowing Medical Institute - Up to Involving My Deadly Leukemia B-CLL! All of these Events was said to be caused and caused entirely by medical processes within the normal limits of the rules of "Lege Artis CZ". So, I consider myself a state mockery scientist for my public state execution - as protesting expert in Cybernetics and an OSH expert, as the creator of harmonized EU / Czech implant law - I seems to be a worldwide Scandal within the scope of the WHO organization and with a strong warning to keep Patient Human Rights from all OECD countries carefully!.

My medical and judicial case can only be compared with the unnecessary medieval burning of the Reformer Master Jan Hus in Constance in 1415 for his courageous questioning of the false aura of the divine infallibility of the then Pope and the then Emperor Zikmund Lucemburský - a Czech scholar protesting against the godless fraudulent act of absolutism to sell in Europe "God's pardons"! I have a simple detection method for all hospital networks and for all OECD Orthopedic Clinics, how to massively detect mass occurrences of technically illegal medical processes. First of all, it is necessary to proceed from the criminological propositional logic - according to which any sequence of partial medical activities consisting of the preliminary binding quality of the technical and medical acts is always ILLEGAL if it contains any mixture of legal and illegal phenomena with the occurrence of at least one partial illegal activity - i.e. the unlawful technical quality of the partial act or the unlawful completeness and correctness of order and accuracy of the timing of the act in the overall next connected Result „Illegal finished medical orthopaedic process“, definitely!

The calculations will be with samplings carried out by your constitutional computer system within a few minutes of deriving from the complex, complete database of EHRs 2016 - in the sequence of results provided just for your particular hospital or just for your particular Orthopedic Clinic, Orthopedic Radiology Operators, and Summarized then for the whole state - for example the Czech Republic, the USA, and summarily, the results can be summarized in a two-stage sample survey also for 
all OECD countries in an internationally coordinated sampling survey!

Be aware that you only need to have the proper competence of a top management of a hospital member or the appropriate area of trust to carry out the basic probability sampling tests. You may have a solid initial computer support for competent access to data derived from a fully existing database - from the completed files of "EHRs in 2016", you need your calculations for a short time only by your solid experienced programmer and statistician, your experienced and unprejudiced forensic physician or forensic technician - a technician who knows the technical conditions of the legal use of "CE" medical devices. You can then re-qualify and certify your key staff - lead orthopaedic clinic, radiologist, orthopedist, physiotherapist, environmental management and maintenance expert, space organizers, controllers of legal and factual completeness of preoperative clinical documentation, supervisors of special events in individual sections, solutions for the treatment of demanding polytraumat patients, main hall technical halls disasters, IT and power outages, you can qualitatively deal with the support, control of sufficient reserve blood reserve supplies, you can start to automate some preoperative examinations, patient skeleton in 3D geometry mode, computer printing of individual Operation Plan, etc., etc.

Of course, if you have current interest, you can take multilateral statistics samplings to compare - for Examples the effectiveness and credibility of Diagnostics and the choice of individual Therapy, rehabilitation ways, safety medication... in various concurrent comparable hospitals, various standard orthopaedic surgeries, similarly equipped Orthopaedic Clinics, variously declared dynamic various clever Clusters of comparable age of patients with similar pre-operative diagnoses, with similar used implants, with the same preoperative automated computer designed similar Clinic Plans with respect to skeletal individualities of the shape and positions of the bones of each patient.

This proposed system of continuous sampling and automated quality comparison of the standard medical standard works

\section{This work is licensed under Creative}

Commons Attribution 4.0 License

DOI: $10.19080 /$ OROAJ.2018.10.555788 in Orthopedics was published as Utility Model 21532 CR 2010 with detailed descriptions decision-making method S_T_A_R_S - Statistical Retrieval and Search of sufficient Samplings information to share and to reuse parallel (in hospital nets) for Mass. Similar strategic decision making with risks and computer support.....with minimize sum of increases Entropy in Informal working Channels! It is a revolutionaries World visionary Act, remember me: I am just nearly dying for your better Safety Healthy Patient Future! Help me to live too!

Probably my first invention initialized directly from my tragic personal patient experience of multiple concatenation of technical illicit medical errors in the single orthopaedic performance of the Czech Republic and probably the reason for my criminally and medically forced premature close death by the Czech court "LEGE ARTIS CZ", so my unpredictable working doctors over their finished illegal work destructured of my Rest life, they are clearly satisfied perfect. You continue!

In Prague officially authorised signing in Date January 1. 2018. Antonín Cuc, home address: Na Míčánkách 435/1, Prague 10, Czech Republic. The used and contextual Literature: The Regional Court Prague No 36 C 181/2009 Inputs Health Documentation Antonín Cuc, 11/2009. Court Medical Message No 36 C 181/2009-123 since Match 27. 2012. The Standpoint of the Plaintiff Antonín Cuc -protests for the false criminal arguements oc the Court Medical Message of the Knoiwing Institute - The Central Army Hospital Prague - open recommended letter to hands of the Judge JU Dr. Vojtěch Cepl, Regional Court Prague, since August 17, 2012. The Judgement Regional Court Prague No 36 C 181/2009-221 since September 24, 2012

\section{Internet web}

Study Questions Quality of US Health Data.

\section{Commentary}

Hospitals May Sicken Many by Withholding Food and Sleep. It's Time for Transparency/ Contacts: Vanessa McMains 410502-9410 vmcmain1@jhmi.edu

\section{Your next submission with Juniper Publishers will reach you the below assets}

- Quality Editorial service

- Swift Peer Review

- Reprints availability

- E-prints Service

- Manuscript Podcast for convenient understanding

- Global attainment for your research

- Manuscript accessibility in different formats

( Pdf, E-pub, Full Text, Audio)

- Unceasing customer service

Track the below URL for one-step submission

https://juniperpublishers.com/online-submission.php 